\title{
TELEVISIÓN PÚBLICA Y DIVERSIDAD CULTURAL EN ESPAÑA: EL CASO DE LOS PROGRAMAS DIRIGIDOS A «INMIGRANTES»
}

\section{PUBLIC TELEVISION AND CULTURAL DIVERSITY: THE CASE OF PROGRAMS ADDRESSED TO «IMMIGRANTS»}

LAURA NAVARRO*

Resumen: El presente artículo analiza la aparición de los primeros programas televisivos dirigidos a «inmigrantes» en España, desde una perspectiva histórica y sociológica que permite constatar la influencia del contexto social, político y económico del país en la creación -y en muchos casos también desaparición-de estos programas, así como el rol pionero de las televisiones públicas autonómicas y locales en la promoción de este tipo de emisiones. Asimismo, el análisis de la evolución y desaparición de los programas Con todos los acentos (TVE) y Andalucía sin fronteras (Canal Sur $T V)$ pone de manifiesto la comercialización de los contenidos y la precarización de medios técnicos y humanos que se produce -especialmente a partir del 2008 - en estos espacios mediáticos creados, en su origen, para promover la «integración» de la población inmigrante y la divulgación de la "diversidad».

Palabras clave: inmigración, televisión pública, periodistas migrantes, diversidad cultural, racismo.

*Investigadora Université Paris 8, Saint-Denis (Francia), 93526. launagar@ yahoo.es 


\begin{abstract}
This article analyses the emergence of TV programs addressed to "immigrants» in Spain, from an historical and sociological perspective, which shows the influence of social, political and economic context of the country on the creation of these programs, and points out the pioneer role of local and autonomic public televisions on their promotion. In addition, the analysis of the evolution and disappearance of Con todos los acentos (TVE) and Andalucía sin fronteras (Canal Sur TV) shows the commercialisation of contents and the precarization of technical and human resources experienced - specially since 2008 - by these TV programs, which were created at the beginning to promote immigrant population's "integration» and the awareness of "diversity».
\end{abstract}

Keywords: immigration, public television, migrant journalists, cultural diversity, racism

\title{
1. INTRODUCCIÓN
}

El estudio que presenta este artículo se enmarca dentro de una investigación más amplia ${ }^{1}$ que ha tratado de avanzar en la comprensión de la complejidad que envuelve el estudio de las migraciones y los medios de comunicación, interesándose por aquellas dimensiones que - como las políticas públicas en materia de comunicación y diversidad cultural o los espacios mediáticos creados por y/o para la población inmigrante- han quedado a la sombra de otros objetos de estudio más trabajados como, por ejemplo, la representación de la inmigración en los mass media. En concreto, el artículo presenta los resultados de la investigación sobre programas televisivos dirigidos a «inmigrantes» ${ }^{2}$ en España, en especial aquellos emitidos en las televisiones públicas.

1 Proyecto de investigación MEDIAMIGRATERRA sobre «Médias et migrations dans l'espace euro-méditerranéen» (2010-2011), financiado por la ANR).

2 Está entrecomillado para subrayar que nos referimos no al concepto sociológico de inmigrante, sino a la categorización jurídica que - concretizada desde la primera Ley de Extranjería de 1985- ha acabado por instituir socialmente la «inmigración» como extranjera (y extracomunitaria) por definición. 
Hasta ahora, las pocas investigaciones publicadas que han abordado este tema lo han hecho desde el análisis de las representaciones de la alteridad y el formato de estos programas, como la realizada por Ingrid Guardiola (2006), o desde la reflexión sobre la experiencia laboral de los periodistas migrantes y el debate sobre la democratización del campo mediático, como hace Alicia Ferrández (2012) partiendo de la noción de Charles Husband (2000) de "esfera pública multiétnica». Nuestro artículo viene a completar estos análisis abordando el estudio de estos programas televisivos desde una problemática diferente, centrada más bien en la génesis histórica de estos nuevos espacios mediáticos, así como en los intereses políticos y económicos que atraviesan su creación y, en algunos casos también, su desaparición.

Para ello, partimos de los testimonios obtenidos en entrevistas semidirectivas realizadas a profesionales de la comunicación que participaron en la dirección y realización de estas emisiones. En los casos de Con todos los acentos (TVE) y Andalucía sin fronteras (Canal Sur TV), la entrevista pudo realizarse en las mismas instalaciones de la cadena, con lo cual se pudo observar de cerca los recursos técnicos y humanos con los que contaban ambas emisiones, y en el caso andaluz, pudimos incluso compartir una jornada de trabajo con la redacción del programa. A través de estas entrevistas se buscó dar respuesta, principalmente, a las siguientes preguntas: ¿Cuándo empiezan a emitirse estos programas en las televisiones públicas de España? ¿Por qué y con qué objetivos se crean? ¿Qué actores sociales promueven su creación? ¿A quiénes se dirigen? ¿Qué espacio ocupan en el conjunto de la programación y quiénes componen sus redacciones? ¿Cómo han evolucionado y por qué desaparecen algunos de ellos?

Los testimonios recogidos a lo largo de estas entrevistas fueron analizados posteriormente desde la teoría de los campos de Pierre Bourdieu (2005), con el fin de indagar no sólo en los procesos y las condiciones de producción de contenidos dentro del campo periodístico, sino también en la relación del campo periodístico con el económico y el político. De acuerdo con la teoría de Bourdieu, dichos procesos y relaciones tienden a favorecer formatos televisivos más comerciales y menos críticos; y nosotros buscábamos constatar (o no) dicha tendencia en el caso concreto de los programas dedicados a la población inmigrante y a la divulgación de la diversidad cultural.

Antes de realizar las entrevistas, como trabajo previo de documentación, se realizó una búsqueda de fuentes bibliográficas donde se analizaran los contenidos de estos programas y sus representaciones del 
«inmigrante», así como de artículos de prensa donde se informara de la presentación pública y la desaparición de algunos de estos programas o donde se entrevistara a algunos de sus presentadores. También se analizaron los contenidos de las páginas web de los programas que disponían de ella. Y por último, se visionaron decenas de capítulos de estos programas: en el caso de Con todos los acentos y Babel en TVE, a través de su página web, y el de Andalucía sin fronteras, durante varias estancias en Sevilla y Córdoba entre el 2008 y 2010.

En primer lugar, el artículo aborda el origen de dos programas de televisión pioneros en España: Infos idiomes (Barcelona Televisió) y, en especial, Andalucía sin fronteras (Canal Sur TV), para después detenerse en la aparición y evolución del primer programa de TVE dirigido a la población inmigrante, Con todos los acentos, y su posterior sustitución por el programa Babel en $T V$. El objetivo principal: profundizar no tanto en el análisis del contenido de estas cuatro emisiones, sino más bien en el análisis histórico y sociológico de los contextos políticos, económicos y sociales en los que surgen estas iniciativas, así como de los actores sociales que hicieron posible su puesta en marcha, y los diferentes intereses en juego.

\section{INFOS IDIOMES Y ANDALUCÍA SIN FRONTERAS}

Los primeros programas dirigidos a «inmigrantes» empiezan a emitirse a finales de los 90 y principios del 2000 en Cataluña y Andalucía, dos comunidades autónomas con un porcentaje de población inmigrante más alto que la media española y donde destacan desde muy pronto los movimientos sociales dedicados a la lucha contra el racismo. Se trata, además, de un momento histórico en el que España se convierte en un país de inmigración (Arango, 2000); y en el que, por otra parte, el fenómeno migratorio empieza a convertirse en un tema de división política y el "problema de la inmigración» empieza a aparecer en los discursos públicos (políticos y mediáticos), siendo representativo de este clima la aprobación de varias leyes de extranjería en el breve espacio de tres años.

En el caso catalán, cabe destacar que, a finales de los 90, esta comunidad autónoma se caracteriza no sólo por el alto porcentaje de población inmigrante residente en su territorio, sino también por el dinamismo de las asociaciones, incluidas las de periodistas. Los primeros 
actores sociales que, en España, se interesan por la representación mediática de las minorías étnicas surgen en Cataluña a principios de los 90, en un contexto migratorio particular marcado por la histórica tradición inmigratoria catalana —que ha determinado el perfil demográfico y la estructura económica y social de esta comunidad-, además de por su condición de "nación minoritaria» ${ }^{3}$, que hace que la llegada de inmigrantes extracomunitarios traiga consigo debates políticos e identitarios particulares. El rol de estos actores, entre los que destacan la sociedad civil catalana y la Comisió de Periodisme Solidari del Col.legi de Periodistes de Catalunya, pero también la universidad y la administración catalanas, son analizados en profundidad en otro artículo (cf. Navarro, 2014a), resultante del mismo proyecto de investigación del que forma parte este estudio y en el que se analiza la génesis y la evolución de las políticas públicas españolas en materia de comunicación y diversidad cultural.

En dicho artículo, se profundiza en la creación, evolución, contenidos, objetivos y originalidad de un programa pionero en España y emblemático en este campo: Infos Idiomes, emitido en la televisión pública local Barcelona Televisió (BTV) desde 1998 hasta enero del 2013. Un programa, cuyo objetivo, como se definía en su web, era «facilitar el coneixement de liactualitat barcelonina a les diferents comunitats que conviuen a la ciutat de manera que se n`afavoreixi la integració » ${ }^{4}$, y entre cuyas particularidades destacaba su modelo lingüístico (en el que cada comunidad inmigrante hablaba en su lengua de origen durante todo el informativo) y su modelo de producción (en el que se cedía la iniciativa a las propias comunidades inmigrantes). Aunque un análisis detallado de los contenidos de los informativos así como la financiación de las asociaciones, institutos de cultura y consulados que participan en su producción nos llevarían a plantear nuevas representaciones sesgadas, ligadas generalmente a los vínculos políticos e institucionales de muchas de estas entidades, lo cierto es que este modelo posibilitaba la participación activa de las personas inmigrantes en la producción de contenidos, sin limitar su labor a la de meros bustos parlantes. Un papel periodístico activo que brillará por su ausencia en algunas etapas de las emisiones "para inmigrantes» que veremos a continuación; especialmente en el programa Babel en TVE, donde en ningún momento se

\footnotetext{
3 Término utilizado entre otros autores por Zapata-Barrero (2008).
}

4 www.btv.cat/btvnoticies/especials/infosidiomes/ 
contará con periodistas de origen extranjero en la redacción y donde ni siquiera veremos presentadores «inmigrantes».

En la televisión autonómica catalana (Televisió de Catalunya), también encontramos desde 2001 diferentes programas donde la población inmigrante es protagonista. El primero de ellos fue Karakia, una emisión emblemática dedicada a la gastronomía de los países de las diferentes comunidades inmigrantes residentes en Cataluña, que desde octubre de 2001 y hasta hoy, se emite en el segundo canal de la Televisió de Catalunya (Canal 33). Con Karakia, la televisión pública catalana dará el pistoletazo de salida a la promoción y difusión de este tipo de programas de divulgación de la interculturalidad y las migraciones que no se dirigen únicamente a los diferentes colectivos inmigrantes, sino que están pensados también, y sobre todo, para dar a conocer a la población autóctona las culturas y la vida cotidiana de los y las recién llegadas. Tanto Andalucía sin fronteras como Con todos los acentos, se enmarcan dentro de este tipo de programas. Veamos con detenimiento el origen del primero de ellos.

Andalucía sin fronteras nace en 2001. Se trata del primer (y único) espacio que la televisión pública andaluza ha dedicado especialmente a la población inmigrante, y también el primero presentado íntegramente por profesionales procedentes de este colectivo. Para entender bien por qué y cómo surge esta emisión, es importante que nos detengamos en el contexto social y político andaluz de finales de los 90 . En primer lugar, Andalucía, al igual que Cataluña, destaca desde los años 90 por la presencia importante de población inmigrante extranjera en su territorio. Según el INE, en diciembre de 1999, era la comunidad autónoma con más extranjeros (con un 13,62\% de toda la población extranjera residente en España), después de Cataluña (22,93\%) y Madrid (19,83\%).

Otra particularidad de la comunidad andaluza es la presencia temprana del tejido asociativo dedicado a la acogida de la población inmigrante y a la lucha contra el racismo. De hecho, las primeras asociaciones de este tipo surgen en Andalucía a mediados de los años $80^{5}$, antes de la eclosión de ONGs pro-inmigrantes que se producirá en toda España a finales de los años 90. Este tejido asociativo se caracteriza por su compromiso con la defensa de los derechos de las personas inmigrantes, la promoción de la convivencia intercultural y la denuncia del drama de los harraga ahogados en el estrecho de Gibraltar.

5 Las emblemáticas ONGs Sevilla Acoge, fundada en 1985; y Almería Acoge y Granada Acoge en 1987. 
No extraña por tanto que, aunque la televisión pública andaluza no dispuso de un libro de estilo hasta 2004, los medios de comunicación andaluces —desde diarios como Europa Sur en Algeciras a la Radiotelevisión pública andaluza y la Asociación de Emisoras Municipales de Andalucía- fueran, junto con los medios catalanes, pioneros en la elaboración de prontuarios de estilo para evitar discriminaciones racistas en el lenguaje periodístico. Ya en 1989, el diario Europa Sur editó unas normas, internas, que recogían algunos aspectos sobre la inmigración; una inmigración hasta entonces apenas existente en el país, pero que tenía repercusión en dicha zona por el tránsito de inmigrantes marroquíes y argelinos que se dirigían a sus países de origen a pasar las vacaciones.

Es en este contexto, y a raíz de los incidentes racistas sucedidos en 2000 en El Ejido, cuando empieza a emitirse el programa Andalucía sin fronteras. Estos sucesos actuaron como detonante para que, finalmente, tanto las asociaciones de inmigrantes y pro-inmigrantes como administraciones públicas, organizaciones empresariales, ayuntamientos y medios de comunicación, se organizaran para crear en 2001 el Foro Andaluz de la Inmigración, abriendo así un cauce de participación y de debate entre todos los agentes sociales implicados en el fenómeno migratorio. Este foro jugará un papel decisivo en la promoción de «la integración social de los inmigrantes de origen extranjero residentes en Andalucía $»^{6}$ y, en particular, en la creación del programa Andalucía sin fronteras.

Aunque en su origen el formato del programa era más cercano al de un informativo televisivo «orientado a la población extranjera» (del tipo Infos Idiomes), según su antiguo director, Juan José Téllez ${ }^{7}$, periodista fundador de varias revistas contraculturales y galardonado con distintos premios periodísticos y literarios, Andalucía sin fronteras siempre se dirigió tanto a la población inmigrante como a la autóctona, con el objetivo de divulgar la interculturalidad y romper estereotipos sobre esta población:

Desde un principio, la idea del programa no sólo estribaba en crear un espacio donde hubiera cabida para noticias relacionadas con la inmigración. En rigor, pretendíamos ensayar un formato en el que se incorporase a presentadores de diversos orígenes

6 Decreto 55/2001, de 26 de febrero, por el que se regula el Foro Andaluz de la Inmigración. BOJA n ${ }^{\circ} 34$ de 22/03/2001.

7 Entrevista con Juan José Téllez por email, enero/febrero del 2011. 
étnicos o territoriales, pero que no sólo ejercieran como tales sino que se incorporasen también a las tareas de redacción del programa. Queríamos presentar una imagen joven y atractiva de los inmigrantes, para romper con el estereotipo de un imaginario que habitualmente les retrataba en el inconsciente colectivo como seres paupérrimos y agotados por la travesía del Estrecho (J. J. Téllez).

Una apuesta por la integración de los y las «inmigrantes» también en la redacción que no sólo ha sido pionera y excepcional en el contexto de las televisiones públicas autonómicas y estatales (donde la incorporación de estos periodistas a las redacciones, en general, brillaba y sigue brillando por su ausencia), sino que además resulta muy valiosa a la hora de promover un tratamiento informativo más plural y menos etnocéntrico de la inmigración. De hecho, es recomendada por diferentes organismos nacionales e internacionales. Entre estos, el Col.legi de Periodistes de Catalunya y el Consell Àudiovisual Català, impulsores de una guía en la que se recomienda fomentar «la presencia de profesionales de distintos orígenes» como algo no sólo «socialmente justo, sino periodísticamente necesario de cara a la calidad informativa y a la aportación de nuevas miradas sobre la realidad» (CPC et al, 2010); la Alianza de las Civilizaciones de Naciones Unidas, que recomienda que los medios de comunicación promuevan la «newsroom diversity», y que los gobiernos y organizaciones no gubernamentales apoyen este objetivo ${ }^{8}$; o el Consejo de Europa, uno de cuyos informes recomienda incluso "permitir a los periodistas de comunidades minoritarias explicar todos los aspectos de la agenda de los medios y no sólo cuestiones que tengan que ver con sus comunidades», y "permitir intercambios entre periodistas 'issus de différents communautés' que trabajen en medios étnicos o generales» (Consejo de Europa, 2009).

Recomendaciones que, a menudo, chocan con los marcos legales de las propias televisiones y de las propias políticas de empleo, sobre todo cuando se trata de contratar a periodistas que no tienen la nacionalidad española. Como afirma Juan José Téllez recordando los primeros días de Andalucía sin fronteras, tuvieron serias dificultades, de índole legal,

8 Recomendaciones del Seminario internacional Covering Migration: Challenges Met and Unmet, a look at Switzerland, organizado por United Nations Alliance of Civilizations (UNAOC) y el Club Suisse de la Presse, en Berna, el 16 de mayo del 2013. 
a la hora de contratar a presentadores y redactores que fueran inmigrantes, «en un sector profesional donde el paro ya era creciente». Al principio, había 5 o 6 presentadores de distintas nacionalidades (que sólo presentaban el programa), y en la redacción eran todos españoles. Después, incorporaron a tres de ellos al equipo de redacción: uno de ellos el marroquí Ahmed Sefiani, el único periodista de los cuatro programas analizados en la investigación al que pudimos entrevistar, y la venezolana Albania Ferrer, con experiencia profesional en el mundo del periodismo. Finalmente, en la última etapa del programa, cuando tampoco había presentadores, el único periodista extranjero que quedó en la redacción fue Sefiani, quien, aunque no tenía experiencia profesional en periodismo cuando fue contratado, destacaba por su dilatada experiencia en asociaciones de estudiantes marroquíes de Andalucía y por haber creado en esta comunidad una asociación en defensa de los derechos de los palestinos.

El perfil comprometido, tanto del director como de otros periodistas del equipo como Ahmed Sefiani, se reflejaba en los contenidos del programa, y también en las fuentes de información utilizadas, pues el equipo solía priorizar los testimonios de asociaciones y de personas inmigrantes sobre las fuentes institucionales. En cuanto a los contenidos, en palabras de Sefiani $^{9}$, «a parte de informar y ser todo paz y amor en la tierra, sí tratamos la problemática, las políticas de inmigración, espacios de ofertas de trabajo y de consulta jurídica». Y desde el principio, a diferencia del resto de programas analizados, se introdujo un texto de opinión que firmaba Téllez, en el que se imprimía un tono editorial al programa que buscaba ser crítico, sin perder de vista las noticias «en positivo»:

No dejamos nunca de abordar las dificultades por las que atravesaba y atraviesa dicho colectivo — desde el rigor de las leyes, a la infravivienda, desde los CIEs a la precariedad, racismo, xenofobia, maltrato, criminalización del colectivo, redes de tratas, etc.- , pero también apostamos por incorporar noticias en positivo, desde la aportación de la comunidad inmigrante a la demografía o a la cultura, hasta las experiencias de convivencia plena en determinados lugares (J. J. Téllez).

\footnotetext{
9 Entrevista a Ahmed Sefiani en Sevilla, el 2 de febrero 2009.
} 
Las diferentes secciones del programa, en su última etapa, eran las siguientes: "Tres tristes tópicos», dirigido más a españoles, que intentaba desmentir los tópicos sobre las personas inmigrantes; "Cruce de miradas», en el que se comparaban dos opiniones de similar perfil pero de distinto origen (por ejemplo, un sociólogo francés y una socióloga española); "Cosa de niños», en palabras de Sefiani, intentaba «suavizar un poco las cosas dramáticas», planteando preguntas a niños pequeños de culturas diferentes y causando «un efecto gracioso, quitando hierro al asunto»; y, por último, «Por amor al arte», también dirigido a los españoles, centrado en destacar las aportaciones culturales de estos colectivos.

Durante la mayor parte del tiempo que Andalucía sin fronteras estuvo en antena, el programa ofrecía además otro tipo de contenidos de servicio público. Nos referimos al espacio de actualidad, «Al día», donde se trataban temas de interés para los inmigrantes; así como el espacio «Enredados», orientado igualmente al público inmigrante y en el que se mostraban las últimas novedades en Internet. A diferencia de Infos Idiomes, y al igual que los programas que veremos a continuación, el idioma utilizado era el castellano, aunque como recuerda Sefiani, al principio sí hubo «un guiño a los árabes», pues se daba una noticia en árabe, de 30 o 40 segundos, y subtitulada en español; pero fue una idea «que no tuvo gran éxito [de audiencia]» y se dejó de emitir.

A pesar de la importante labor de servicio público de este programa, su presupuesto fue reduciéndose progresivamente y, poco a poco, fue relegado a franjas horarias de menor audiencia. La reducción de presupuesto se reflejó en una disminución progresiva de los medios técnicos y humanos. Y si, en un principio, realizaban entrevistas en directo en el plató de los informativos de Canal Sur TV desde donde se emitía el programa, posteriormente dejaron de utilizar dicho plató para valerse tan sólo de un croma en un estudio auxiliar de la RTVA y estas entrevistas quedaron descartadas. Finalmente, como explica Téllez, «por exigencias de producción y a fin de imprimir mayor ritmo al producto", tuvieron que prescindir de los presentadores, todos ellos de origen extranjero, aunque permanecieron en la redacción.

En cuanto al horario de emisión, durante los primeros cuatro años, Andalucía sin fronteras se estuvo emitiendo los domingos a mediodía, entre el programa religioso y el taurino, salvo en ocasiones especiales o durante los meses de verano en que se interrumpía su programación. Aunque más tarde Andalucía sin fronteras pasó a emitirse el viernes a las doce de la noche, después de un programa de entretenimiento que les 
permitió ganar más audiencia (llegando a estar en la media del canal), sólo duró un año. Después, el horario se cambió al domingo a las doce de la noche, víspera de día laboral, lo cual redujo mucho el número de espectadores.

El tema de la audiencia fue esgrimido no sólo para justificar los cambios de horario, sino también los cambios de formato. Como explica Ahmed Sefiani, fue en esta última etapa, cuando se emitía el domingo a las doce de la noche y tenían menos audiencia, especialmente a partir del 2008, cuando la productora empezó a buscar nuevos formatos, en palabras de Juan José Téllez, «con los que conquistar nuevos espectadores... antes de que muriese por agotamiento». La lucha por la audiencia, por hacer el programa más «vendible», también fue esgrimida a la hora de eliminar ciertas secciones y relegarlas a la página web del programa, como el espacio dedicado a las ofertas de trabajo y la consulta jurídica, que sin embargo, según Sefiani, gozaban de buena audiencia, como lo demuestra "la inmensa cantidad de emails que nos llegaban sobre consultas jurídicas o solicitudes de empleo».

En el verano de 2009, como el share del programa no mejoraba, el director de la productora consiguió que RTVA permitiera la emisión de una nueva temporada de Andalucía Sin Fronteras, pero con un nuevo formato, en palabras de Téllez, «más trepidante, al estilo de los que empezaban a hacer furor a la usanza del programa Callejeros». En paralelo, se brindaba un nuevo espacio titulado Viajeros por Andalucía (que no duró más de una temporada) en el que extranjeros de distinta extracción social pero residentes en la comunidad andaluza ofrecían su visión particular de Andalucía, todo ello conducido por dos presentadores españoles muy mediáticos. «Fue en ese momento en el que dimití por discrepancias personales en dicha orientación del programa», reconoce Téllez. A finales de 2009 murió finalmente el programa.

En definitiva, mientras que la productora del programa intentó buscar alternativas para la pervivencia de Andalucía sin fronteras, la dirección de la cadena no hizo cambios relevantes para intentar aumentar su audiencia, en opinión de Téllez, «bien porque consideraban que dicho formato estaba agotado o bien por otros motivos». Aunque no pudimos contrastar estos motivos con el director de programación de Canal Sur TV, Fidel Cardete (quien no respondió a la solicitud enviada para entrevistarle), tanto el proceso de precarización de medios al que se condujo en los últimos años a este programa (y no a otros) como la comercialización progresiva del formato, ponen en evidencia el alejamiento del objetivo de servicio público por parte de esta cadena, al menos en cuanto a 
la divulgación de interculturalidad y a derechos de personas migrantes se refiere. En la actualidad, Canal Sur TV ya no emite ningún programa ni presentado por «inmigrantes» ni dedicado a la divulgación de la diversidad cultural.

\section{CON TODOS LOS ACENTOS}

Hay que esperar al 2005 para encontrar el primer programa de la televisión pública española (TVE) dedicado a la inmigración y la interculturalidad: Con todos los acentos, una emisión semanal que fue emitida hasta 2009 en La 2. De acuerdo con José Morillas ${ }^{10}$, antiguo director del programa, periodista, sociólogo y militante activo en uno de los sindicatos de RTVE, Con todos los acentos nace básicamente gracias a la iniciativa de Delfina Simón, una periodista de TVE con una sensibilidad especial por el tema de la inmigración, que propone un proyecto a la dirección de TVE y pelea por que se lleve a cabo. A la hora de elaborar el proyecto del programa, Simón busca diferenciarse de muchas emisiones "para inmigrantes» que ya existían en algunas televisiones públicas autonómicas. Como recuerda José Morillas, «el programa debía sobre todo representar a todos [...]Era un programa para que se encontraran los inmigrantes con los ciudadanos españoles».

La propuesta de Delfina Simón tuvo eco en la dirección de TVE en un momento político y unas circunstancias políticas concretas. En 2004, el PSOE gana las elecciones generales y, aunque el cambio de gobierno no implica grandes transformaciones en el fondo de la política española de inmigración — basada, como en el resto de países de la Unión Europea, en criterios de control y de orden público (De Lucas, 2008)—, se producen algunas evoluciones con respecto al gobierno anterior. Por una parte, el discurso político del nuevo gobierno sobre inmigración es menos problematizador que el del gobierno anterior, y por primera vez, se empieza a poner en marcha activamente iniciativas dirigidas a la «integración de inmigrantes», donde se tiene en cuenta la dimensión mediática (Navarro, 2014a). Por otra parte, 2005 fue el año en que el gobierno español aprueba una regularización extraordinaria de personas inmigrantes; una decisión que fue muy criticada por el Partido Popular,

10 Entrevista con José Morillas en Madrid, el 28 de julio de 2010. 
cuyo discurso alarmante incidió en calificar esta regularización de «masiva» y responsable de un «efecto llamada». En ese contexto, la creación de un programa que, en principio, buscaba ofrecer una cara más amable de estas personas, vendría a contrarrestar dichas críticas y a legitimar la necesidad de una regularización de este tipo.

En 2006, pocos meses después de crearse Con todos los acentos, se aprueba el Plan de saneamiento de RTVE, con el que se produce un recorte importante de plantilla y de gastos. Tras el expediente de regulación de empleo (ERE) llevado a cabo, 4.150 profesionales dejan de trabajar para RTVE, entre ellos Delfina Simón. José Morillas pasa entonces a ocupar el cargo de director del programa y a seguir la línea editorial de Simón, caracterizada por un marcado carácter de servicio público. En el dossier del programa, se define al programa como «un espacio de la televisión pública estatal para la integración de los ciudadanos». Morillas resume así los tres objetivos principales de Con todos los acentos:

[Primero:] visualizar a los inmigrantes como ciudadanos de primer orden [...] no como una población marginal, ni como una invasión ni como un problema [...], sino como ciudadanos que están en este país, que se merecen un respeto y un derecho a la ciudadanía como otro cualquiera. [Segundo:] subrayar su papel en el empujón que dieron a la bonanza económica del país, en términos económicos, en términos demográficos, en términos culturales, humanos. [Tercero:] el espacio tenía que darles voz [...] Lo que no queríamos es que nadie hablara en boca de otros. Queríamos que ellos fueran protagonistas (J. Morillas).

Esta reflexión es la que, en buena medida, condiciona los diferentes contenidos del programa y también su formato, con un plató planteado como un punto de acogida con colores, redondo, con la frase "con todos los acentos» traducida en diferentes idiomas y con el artículo 13 de la Declaración Universal de Derechos Humanos. El programa se dirigía a la población inmigrante, pero sin perder de vista al público autóctono. De hecho, Con todos los acentos tenía contenidos pensados especialmente para la población española: como la sección "Con otra mirada», descrito en la página web de TVE como un «documental abierto a asuntos de interés con sus protagonistas» con el que se trataba de «saber quiénes son, qué los ha traído hasta aquí, cómo viven, cómo piensan, cómo se sienten, sus dificultades 
[...] sus sueños y sus añoranzas» ${ }^{11}$. Y otras secciones pensadas sobre todo para el público inmigrante: como "Consultas», donde la gente acudía al plató para pedir asesoría jurídica a abogados expertos en extranjería; y «Esta Semana», que abordaba «un hecho noticioso de servicio público y de interés específico" para el colectivo inmigrante. Las otras secciones eran: "Platos de domingo», dedicada a la gastronomía; "Agenda», sobre actos e iniciativas sobre migración e interculturalidad programados para la semana siguiente ; y por último, "Mosaico», dirigida a "conectar con un amplio abanico de culturas en todas sus expresiones, música, arte, literatura, artesanía, danza, deporte, teatro, folklore, etc.» ${ }^{12}$.

En la sección de "Consultas», se trataban casos escogidos a petición de los y las espectadoras; por ejemplo, cómo solicitar un visado de turista, cómo resolver una irregularidad provocada por la pérdida del empleo, qué hacer ante una solicitud de arraigo desestimada o ante una reagrupación denegada por un consulado, o cómo solicitar el permiso de residencia en el caso de padres inmigrantes con hijos nacidos en España. Además, la sección suponía traer a «inmigrantes» al plató y tratarlos, en palabras de José Morillas, «como a ministros». Se trataba, por tanto, de un espacio de gran valor simbólico, por la importancia de contar con expertos en extranjería que ayudaban a los espectadores del programa a resolver problemas legales de gran relevancia para sus vidas, pero también por la importancia concedida a los cuerpos inmigrantes; cuerpos que, en esta sección, pasaban a ser sujetos activos a quienes no sólo se les daba la palabra para hablar, sino que además se les recibía como a valiosos invitados. Una presencia y un papel de los cuerpos inmigrantes que, en definitiva, contribuían a erosionar la imagen dominante del «inmigrante» como objeto de intervención social y a construir una mucho menos presente en el discurso informativo hegemónico: la imagen de estas personas como ciudadanos con plenos derechos. Y es que como puede leerse todavía hoy en la web de TVE: "Con todos los acentos quiere ofrecer a los ciudadanos inmigrantes un espacio para informarse, para reconocerse, para intercambiar experiencias, para asesorarse, para denunciar y por supuesto para entretenerse».

Este carácter crítico y reivindicativo se reflejaba igualmente en la elección del tema de los reportajes y, sobre todo, en su tratamiento, en el que no

11 www.rtve.es/\%20class=l?go=eacaa4148f48af89730076a6669df2169fcb5b 71e1aa29da9059aec6a85b883014186b1353a64578d2d7d0252b3e688e

12 Idem. 
solían faltar explicaciones políticas e históricas para contextualizar el drama, la historia o la práctica cultural de la que se nos estaba informando. A modo de ejemplo, citaremos los temas de los reportajes con los que se abrían los últimos cinco programas de Con todos los acentos colgados en la web de TVE ${ }^{13}$; programas visionados por última vez el día 3 de julio de 2013, justo antes de enviar el presente artículo a la revista para su evaluación:

- 28-6-09: «Deportación de un inmigrante senegalés en el aeropuerto de Barajas», en el que se muestran las imágenes grabadas por un periodista que viajaba en el mismo avión (en las que aparecen varios agentes golpeando a un ciudadano senegalés), y se recogen testimonios de Amnistía internacional denunciando las malas prácticas en el trato a las personas deportadas, así como testimonios de la policía española.

- 5-7-09: «Mandarina argentina», sobre el caso de una mujer inmigrante argentina que trabajaba de payasa y maga.

- 12-7-09: «Más que un club», sobre el deporte, en concreto el baseball, como lugar de encuentro en una localidad gallega de Rías Bajas.

- 19-7-09: «Dormir en España... Vivir en tierra de nadie», sobre el drama de los bengalíes en Melilla.

- 26-7-09: este día el programa se abre con dos reportajes: el primero, titulado «Acordes del Este», sobre músicos inmigrantes, y el segundo, sobre la nueva ley italiana que declara delincuentes a los inmigrantes indocumentados (en el cual se trata la Directiva de retorno aprobada por el Parlamento europeo, también llamada la Directiva de la vergüenza).

El espíritu crítico del programa se pone de manifiesto, asimismo, cuando José Morillas habla de la publicidad. Tal y como explica, Con todos los acentos sólo tuvo un patrocinio a lo largo de sus cuatro años de vida: uno del banco Santander. Tuvieron también ofertas de Telefónica y de Western Union para incluir pequeñas cuñas publicitarias dentro del espacio "Consultas», pero Morillas no aceptó el formato propuesto porque, entre otras razones, perjudicaba la credibilidad del programa y de los presentadores; y apostó siempre por evitar lo que denomina «hipotecas de contenido»: «es decir, que si yo por ejemplo mañana quiero denunciar a Iberia... no quiero tener hipotecas con ellos. En eso se basa la libertad mía como periodista. Esa es la ventaja de la televisión pública».

13 www.rtve.es/alacarta/videos/con-todos-los-acentos/ 
Al igual que el director de Andalucía sin fronteras, Morillas también encontró dificultades para contratar a periodistas extranjeros. Y así, aunque los presentadores eran extranjeros, todos los redactores contratados del equipo eran, de hecho, españoles. Al principio, el programa estaba presentado por la marroquí Sanaá Harraki y el colombiano Henry Molano, ambos con experiencia previa en el mundo del periodismo. En 2007, Henry Molano deja de presentar el programa y en su lugar entra Eduardo Noda. Posteriormente, Harraki dejó el programa y tres periodistas extrajeras más pasaron a presentar el programa junto con Noda: Angélica Garzón, Arina Gruia y Xiaoqing Zhou.

Como explica en la entrevista, Morillas quería que algunos periodistas del programa fueran extranjeros, pero no fue posible, porque se dedicaba un presupuesto muy marginal a estos programas y, por tanto, no se permitían contrataciones de periodistas que no estuvieran en la plantilla de TVE. El tener dos miembros del equipo extranjeros «ya fue un esfuerzo", y fue posible porque fueron contratados como presentadores (no como periodistas). También intentó que hicieran redactores a los presentadores, pero no lo consiguió, aunque muchos de ellos, como explica, participaron activamente en la búsqueda y tratamiento de temas, e incluso en la redacción de reportajes.

Otra controversia que también destaca, al igual que Juan José Téllez con Andalucía sin fronteras, es la "guerra del horario» que mantuvo con la dirección de TVE para sacar el programa de la franja horaria en la que estaba inserto (los domingos por las mañanas justo después de los programas dirigidos a las comunidades religiosas musulmana, protestante y judía, y antes de los programas para la comunidad católica) y que lo pusieran los sábados junto a programas como Agrosfera, con un perfil de audiencia más preocupada por temas sociales y fuera del ámbito religioso. A esta demanda, se negaron argumentando que la Conferencia Episcopal decía que tenía que haber un programa —en este caso, Con todos los acentos - que sirviera para separar la programación religiosa católica de la programación religiosa no católica.

\section{BABEL EN TVE}

En el año 2009, Con todos los acentos desaparece y TVE empieza a emitir en su lugar Babel en TVE. Para comprender bien por qué se produce este cambio de programa, nos remontaremos al año 2008, 
cuando el primero de ellos empieza a recibir las primeras críticas por parte de la dirección de TVE. Como explica José Morillas, a partir de ese año se produce un cambio de sensibilidad en la dirección de TVE y empieza a recibir las primeras críticas de que «el programa se está quedando anticuado», que por qué no se reduce su duración y se quitan el plató y, en definitiva, por qué no se hace «una cosa más fresquita». Propuestas de cambios que Morillas no está dispuesto a aceptar.

Una vez más, el cambio de sensibilidad de la dirección de TVE respecto al tema de la inmigración se produce en un momento político y en unas circunstancias sociales muy concretas. De hecho, el año 2008 está marcado por la visibilización de la «crisis» en España y por la reorientación de la política de inmigración del PSOE que, tras ganar las elecciones generales de ese año, anuncia una serie de medidas destinadas a disminuir el número de residentes extranjeros, por entonces 5,2 millones, casi el $11 \%$ de la población española. Medidas como la reducción de la contratación en origen, la implementación de un Plan de Retorno, el aumento del periodo de internamiento en los CIEs y los retrocesos en el derecho al reagrupamiento familiar, se justificarán con la crisis económica, el aumento del paro y las dificultades crecientes del Estado del Bienestar (Torres, 2008).

Por otra parte, años antes, con el Plan de saneamiento de RTVE en 2006, como hemos comentado anteriormente, se produce un recorte importante de plantilla y de gastos. El recorte de presupuesto será calificado por algunos autores, como Enrique Bustamante (citado por León, 2011), de «insuficiente» para cubrir los costes operativos y de programación. Y de acuerdo con José Morillas, esta reducción de medios técnicos y humanos afectará especialmente al presupuesto asignado a los programas de servicio público, perjudicando en general a la calidad de la programación de La 2 y haciendo bajar todavía más los índices de audiencia de esta cadena dedicada tradicionalmente a la cultura y a la educación, incluidas la audiencia de Con todos los acentos y la de programas emblemáticos como la Mandrágora, Metrópolis y La aventura del saber.

Después del Plan de saneamiento del 2006, el equipo del programa pasó de tener nueve redactores a ocho y, más tarde, a cuatro. Pero «el segundo golpe», en palabras de Morillas, llegó cuando la dirección de TVE decidió dejarle únicamente con dos redactores (y después, con uno solo); una situación que sí les obligó a repensar los contenidos del programa, así como a realizar muchas más horas de las acordadas en 
los contratos. A esta situación, se opuso Morillas y otros directores de programas de La 2 que, como el de Agrosfera, se oponían también a la reducción del presupuesto dedicado a estos programas. Llevaron este problema a la Comisión parlamentaria que controla la labor de servicio público de la televisión pública, esta se hizo eco, pero al final, los «directores incómodos» que se opusieron a este recorte de forma abierta fueron cesados en agosto del 2009.

En resumen, la desaparición de Con todos los acentos se enmarca dentro del proceso de precarización de los programas de La 2 de TVE y dentro de una política de contenidos interesada en promocionar más otro tipo de programas más comerciales:

A Carlos Fernández [director de programación de TVE de 2007 hasta 2009], cuando le llegaba un productor ejecutivo o un productor de programas con un programa de La 2, le despachaba rápido: «ino quiero saber nada de los programas de La 2!, no me importa, no es mi problema». Él sólo quería saber los programas que daban audiencia y que daban dinero, que eran «Gente», «Corazón», «España Directo», «Mira quien Baila»... De hecho, ellos mismos acuñaron el término de "programas de tercera división» [para los programas de La 2] (J. Morillas).

Sin embargo, como explica José Morillas, cuando el presidente de RTVE o la directora general de RTVE iban al Parlamento a comparecer, en casi todas las comparecencias mencionaban Con todos los acentos y Agrosfera para justificar la labor de servicio público de la radiotelevisión pública. A pesar de este hecho y a pesar de que el programa había recibido varios premios por su trabajo en favor de la integración social y los derechos humanos (entre otros, el Premio de la Cruz Roja Española y el Premio del Consejo General de la Abogacía Española), el programa desaparece en 2009 y en su lugar empieza a emitirse Babel en TVE.

Este cambio no parece responder a objetivos de ahorro si tenemos en cuenta que la producción del nuevo programa se externaliza y, por tanto, TVE tiene que pagar a una productora audiovisual privada los gastos de producción y realización de Babel en TVE (cuyo equipo está formado por 12 profesionales). Y además, tiene que seguir pagando parte de los gastos de producción y realización de Con todos los acentos puesto que, excepto los dos presentadores (cuyo contrato finaliza cuando desaparece el programa), el resto del equipo era "gasto interno» (es 
decir, profesionales fijos de la casa) que, por tanto, sigue cobrando sus salarios aunque haya desaparecido el programa.

Es difícil saber hasta qué punto el cambio de programa ha supuesto o no un ahorro para TVE porque, al no haber podido entrevistar a Carlos Fernández, director de programación de TVE del 2007 al 2009, ni tampoco al responsable del equipo de Babel en $T V E^{14}$, no hemos podido conocer los gastos exactos de producción y realización del programa. Ahora bien, las críticas - e incluso censura de algunos reportajes-que recibió Con todos los acentos en varias ocasiones por parte de la dirección de TVE, sí ponen en evidencia claras desavenencias ideológicas entre los intereses de la dirección de la cadena y la línea editorial del programa. Desavenencias en las que se apoya Morillas para sostener que la creación de Babel en TVE sirvió de "pretexto» en el Parlamento para poder deshacerse de un programa «incómodo» como Con todos los acentos y seguir manteniendo un espacio televisivo, en teoría de servicio público sobre diversidad cultural, pero con una línea editorial menos crítica con las políticas de inmigración del gobierno español.

De hecho, cuando se crea Babel en TVE, como explica Morillas, «todo lo que ellos decían que era árido se quitó»: tanto a los presentadores extranjeros como el plató y la presencia de abogados invitados que denunciaban casos de vulneración de derechos humanos, como por ejemplo la existencia de redadas racistas realizadas por la policía en algunos barrios. Este tipo de denuncias, realizadas por abogados del Consejo General de la Abogacía Española en el plató, no gustaban a la dirección de TVE, que empezó criticándolas y continuó prohibiendo algunos reportajes elaborados sobre este y otros temas incómodos como las críticas lanzadas por una activista a las subvenciones públicas que reciben algunas asociaciones de inmigrantes y que a veces acaban generando prácticas clientelistas.

Así pues, aunque Babel en TVE aporta, como puede leerse en su web, «una mirada plural y cómplice a un fenómeno social, la inmigración, que día a día contribuye de manera crucial a conformar la España del siglo XXI» ${ }^{15}$, también es cierto que en él no encontramos este tipo de denuncias. Y es que Babel en TVE se define en su web como «la revista de la diversidad de TVE», dirigida al conjunto de los ciudadanos, donde la prioridad es aportar esa cotidianidad de la vida de los inmigrantes (que

14 El primero no quiso ser entrevistado y el segundo no respondió a nuestra solicitud.

15 www.rtve.es/television/babel 
suele desaparecer en el discurso mediático hegemónico) y acercar sus culturas y formas de vida a la población autóctona; en síntesis, ofrecer «una nueva forma de conocernos mejor conociéndolos mejor» ${ }^{16}$.

En su página web, también podemos encontrar los contenidos de las cuatro secciones del programa, dirigido en el 2013 por la periodista Carme Nicolàs: «El reportaje», que ofrece «una mirada plural a la actualidad de ámbito general, fomentando la convivencia y el conocimiento mutuo»; "Sabores del mundo», donde "descubrimos que la comida es cultura, un elemento distintivo de los pueblos»; "Caleidoscopio», que ofrece "relatos de la vida cotidiana, una muestra de cómo la presencia en el país de población inmigrante, con orígenes diversos, nos ha enriquecido con sus aportaciones y manifestaciones culturales y religiosas»; y «Personajes», que ofrece "las voces de tantos protagonista de la España diversa». Aunque estos objetivos y temáticas acercan a Babel en TVE a muchos de los objetivos de los programas que hemos visto anteriormente y que contribuyen a ofrecer una imagen más plural y humana que la que predomina en el discurso mediático hegemónico (especialmente en el informativo), hay otras cuestiones que lo alejan de Con todos los acentos y Andalucía sin fronteras.

Por una parte, el objetivo crítico de denuncia social y política de estos dos programas no está presente ni en los principios fundadores de Babel en TVE, ni tampoco se observa en sus contenidos. Y, aunque se ha observado a lo largo de sus casi cuatro años de vida una evolución hacia una mayor complejidad y diversidad de los temas a tratar, hay algunos asuntos (como las redadas ilegales a inmigrantes o los casos de racismo institucional) que siguen sin tratarse. A modo de muestra, podemos citar los temas tratados en los últimos cinco videos de la sección «Reportaje», visionados en la página web de Babel en TVE el 3 de julio del 2013:

- 16-6-2013: "Volver a empezar de nuevo», sobre el retorno de muchos inmigrantes a sus países como consecuencia en la «crisis» en España.

- 9-6-2013: «Sin miedo a salir del armario», sobre la homosexualidad en el colectivo inmigrante.

- 19-5-2013: «Sin miedo al fracaso», sobre emprendedores inmigrantes.

- 12-5-2013: «Juegos de paz», sobre un teatro de marionetas en el que se habla del derecho a disfrutar de la infancia.

- 5-5-2013: «Un futuro mutilado», sobre la mutilación genital femenina.

16 Idem. 
Todos estos reportajes son, además, realizados desde una perspectiva humana y positiva muy valiosa que da la voz y el protagonismo a los propios inmigrantes (de hecho, el programa ha recibido diferentes premios también por el tratamiento periodístico de la diversidad cultural como el Premio para la Diversidad en el Audiovisual en el año 2011, así como el Premio Periodístico «Carmen Goes» de Melilla), pero sin cuestionar el marco político o legal responsable de muchas de las problemáticas sociales, económicas y culturales de las que nos están informando.

Por otra parte, una segunda cuestión que lo aleja de Con todos los acentos y Andalucía sin fronteras tiene que ver más con el objetivo de hacer partícipes a los inmigrantes, de integrarlos, dentro del propio proceso de producción informativa y cultural. De hecho, a diferencia de estos dos programas, en Babel en TVE no aparecen «inmigrantes» en el plató, ni para acudir al consultorio jurídico ni para presentar el programa. Y, aunque es cierto que el programa cuenta con importantes canales que, como Facebook y su página web, ofrecen vías para interactuar con los espectadores (autóctonos e inmigrantes), quienes incluso pueden proponer temas, hay que destacar igualmente que la redacción de Babel en TVE no cuenta con ningún periodista de origen extranjero ${ }^{17}$. Babel en TVE finaliza su emisión el 20 de diciembre del $2013^{18}$

\section{CONCLUSIONES}

Entre los mecanismos desarrollados por las televisiones públicas para dar a conocer la nueva realidad migratoria del país y responder a las necesidades de las personas recién llegadas, destaca la creación, a partir de finales de los años 90, de programas informativos y educativos que, en general, han abordado la nueva realidad social en clave de diálogo, yendo a menudo más allá de los exotismos y, en algunos casos incluso, denunciando los abusos de poder de determinadas políticas gubernamentales. Como se ha tratado de mostrar

17 Hasta el 2011, podía verse en su página web una foto con los miembros del equipo del programa y sus nombres.

18 En el momento en el que finaliza la presente investigación, este programa seguía en antena, con lo cual no han podido analizarse las causas de su desaparición. 
en estas páginas, se trata de un fenómeno mediático reciente, en cuya génesis la sociedad civil organizada ha jugado un papel determinante, y en el que han sido pioneras las televisiones locales y autonómicas; programas que - aunque algunos estudios hayan cuestionado su seguimiento por parte de la población inmigrante (Altarriba, 2008) — han aportado mayor pluralidad a nuestras televisiones, no sólo en lo referente a contenidos sobre las migraciones, sino también en cuanto a la inclusión de diversidad cultural en sus redacciones.

De hecho, a día de hoy, este tipo de programas representa una de las pocas puertas que han abierto las televisiones públicas a los periodistas de minorías étnicas, cuya integración profesional viene siendo reclamada activamente desde $2008^{19}$ y que, hasta el cambio de siglo, se limitaba a casos excepcionales ${ }^{20}$; una integración que, como hemos visto, ha sido recomendada por diferentes organismos nacionales e internacionales. Por otra parte, de acuerdo con estudios como el de Ingrid Guardiola (2006: 147), estos programas dedicados a las migraciones y a la divulgación de la diversidad cultural realizan además un trabajo importante en la construcción de nuevas representaciones de la inmigración (diferentes a las representaciones estereotipadas construidas por el discurso informativo televisivo dominante), nuevos formatos (más didácticos), nuevos temas de información y personajes, otro tratamiento de la diferencia, así como un trabajo con las instituciones públicas "para hacer del programa un auténtico bien público al servicio del interés general».

Ahora bien, nuestra investigación ha revelado igualmente algunas lagunas presentes en estos programas; lagunas que tienen mucho que ver con las tensiones existentes entre el campo periodístico y el campo político y económico, y que convierten al campo periodístico en un campo muy poco autónomo. En concreto, nuestro análisis histórico y sociológico ha puesto en evidencia cómo la hegemonía de una forma comercial de entender la televisión pública — que ha sido por su parte constatada en TVE por autores como Bienvenido León (2011) y Ana Azurmendi (2007) - repercute no sólo en las condiciones y medios

19 Por ejemplo, en las «I Jornadas de Periodistas de Medios para la Inmigración. Periodistas de aquí y de allá: información de todos» (Barcelona, 14 y 15 de noviembre del 2008).

20 Como el de la periodista Francine Gálvez, nacida en Camerún, que presentó el telediario de TVE a principios de los años 90. 
(técnicos y humanos) de producción de estos programas dedicados a promover la «integración» de las personas inmigrantes, sino también en sus contenidos.

En efecto, la evolución de Andalucía sin fronteras y, sobre todo, la sustitución de Con todos los acentos por Babel en TVE, reflejan dos tendencias muy claras en sendas televisiones. Por una parte, la tendencia a precarizar las condiciones de producción y realización de los programas donde, precisamente, las personas inmigrantes pueden ejercer su derecho a comunicar en el plató y también en la redacción, y que acaban desapareciendo finalmente. Por otra parte, la tendencia hacia una forma comercial de entender, y divulgar, los contenidos interculturales, es decir, hacia una visión más despolitizada de la diversidad cultural que prima los aspectos anecdóticos, emotivos y psicológicos sobre los aspectos políticos y reivindicativos. Una visión que trata de reforzar una percepción social positiva de la inmigración y cuyos objetivos sociales son, por consiguiente, muy valiosos (en el sentido de humanizar a estas personas y dar a conocer sus experiencias personales), pero que acaba dejando en un segundo plano (cuando no directamente olvidando) la visión política y crítica de lo intercultural.

Una visión esta última más presente, precisamente, en los programas ya desaparecidos Andalucía sin fronteras y Con todos los acentos, donde no sólo se buscaba desmontar los estereotipos racistas y profundizar en las dimensiones culturales mencionadas anteriormente, sino también visibilizar y tratar problemáticas políticas, sociales y económicas como el derecho al voto, la explotación laboral, los ataques racistas violentos, la guetización de determinados barrios y escuelas públicas, el racismo institucional, y como no, la denuncia de las muertes de miles de personas en su intento de cruzar el Estrecho. Problemáticas que, además, solían contar en sendos programas con explicaciones políticas e históricas que aludían a menudo a cuestiones tan poco tratadas en el discurso informativo hegemónico, como la responsabilidad de los gobiernos europeos en dichos dramas o las consecuencias todavía hoy palpables de la colonización. Programas desaparecidos que, en definitiva, buscaban contribuir, desde los medios, a la construcción de una sociedad intercultural, entendida en su sentido crítico, es decir, como una sociedad donde no sólo es fundamental el respeto a las diferencias culturales, sino también la igualdad de derechos (sociales, económicos, políticos y también culturales) entre todas las personas. 


\section{BIBLIOGRAFÍA CITADA}

Altarriba, M. (dir.) (2008): Usos i actituds dels immigrants davant dels mitjans de comunicació. Grup de recerca TECCIP (Tecnologia, Comunicació, Ciutadania i Participació), Universitat Ramon Llull.

Arango, J. (2000): «Becoming a country of immigration at the end of the Twentieth century: The case of Spain». En King, R., LARARIDIs, G. y TsarDANIDIS, D. (eds.), Eldorado or Fortress ? Migration in Southern Europe. Londres, McMillan Press, pp. 253-276.

Azurmendi, A. (dir.) (2007): La reforma de la televisión pública española. Valencia, Tirant lo Blanch.

LEÓN, B. (2011). «La televisión pública española ante el nuevo paradigma comunicativo». En LEón, B. (coord.), La televisión pública a examen. Comunicación Social, pp. 19-32.

Bourdieu, P. (2005): «The Political Field, the Social Field, and the Journalistic Field». En Benson, R. y Neveu, E. (eds.), Bourdieu and the Journalistic Field. Cambridge, Polity Press, pp. 29-47.

Consejo de Europa (2009): Rapport Média \& Diversité: Promouvoir l'accès des minorités aux media. Campagne du Conseil de l'Europe «Dites non à la discrimination».

CPC et al. (2010): Guía sobre el tratamiento de la diversidad cultural en los medios de comunicación. Barcelona, CPC/CAC/Generalitat de Catalunya/ Pla Integral del Poble Gitano/Centre UNESCO de Catalunya.

DE LuCAS, J. (2008): «Integración política, participación y ciudadanía». En García Roca, J. y LAcomba, J. (eds.), La inmigración en la sociedad española. Barcelona, Bellaterra.

FERrández, A. (2012): «Sobre la experiencia laboral de los periodistas migrantes en un contexto de desregulación: entre la precariedad y la democratización del campo mediático». Comunicación y Sociedad, vol. XXV, 2, pp. 305-330.

GuARDIOLA, I. (2006): «Invitaciones a la reconciliación: la inmigración a través de programas divulgativos de proximidad». Quaderns del CAC, 23-24, pp.147-156.

HusBand, Ch. (2000): «Media and the public sphere in multi-ethnic societies», en Cottle, Simon (ed.), Ethnic minorities and the media. Buckingham, Open University Press.

LEón, B. (2011): «La televisión pública española ante el nuevo paradigma comunicativo». En LEón, B. (coord.), La televisión pública a examen. Comunicación Social, pp. 19-32.

NAVARro, L. (2014a): «Políticas públicas, comunicación e inmigración marroquí en España: de la protección de la libertad religiosa a la promoción de la diversidad», Communication \& Society/Comunicación y Sociedad, Vol. 27, n. 2, 2014, pp. 195-219. 
NAvarro, L. (2014b): «Les médias nés des migrations marocaines en Espagne: le droit à communiquer en question». En Mattelart, Tristan (ed.), Médias et migrations dans l'espace euroméditerrannéen. Paris, Éditions Mare \& Martin, collection MediaCritic, pp. 317-360.

Torres, F. (2008): «El cambio en la política de inmigración». Página abierta, 196, pp. 4-8.

ZAPATA-BARRERO, R. (2008): "Immigrazioa eta autogobernua nazio minoritarioetan: Quebec, Flandes eta Katalunia». Jakin, 165, pp. 99-130. 